\title{
Factors Associated With Nutritional Status of Under-Five Children in Yirgalem Town, Southern Ethiopia
}

\author{
Alemneh Kabeta ${ }^{1}$, Dayanand Belagavi ${ }^{1}$, Yordanos Gizachew ${ }^{2}$ \\ ${ }^{I}$ School of Nursing and Midwifery, College of Medicine and Health Sciences, Hawassa University, Ethiopia \\ ${ }^{2}$ Department of Nursing, College of Medicine and Health Sciences, Arbaminch University, Ethiopia
}

\begin{abstract}
Healthy nutritional status is one of the pinpoint to be observed in assessing health status of an individual. It is also used as a direct and indirect indicator body's strength to defend unhealthy happenings. Health statuses of under-five children are among the under-nutrition vulnerable population segments. Thus, this study was conducted to assess factors associated with nutritional status of under-five children in Yirgalem town, southern Ethiopia. A kebele (Lower administrative Unit) was selected using lottery method from kebeles in the town. A community based cross-sectional study design was employed on a total of 398 child and mother/caregiver pairs selected through simple random sampling. Data was collected using semi-structured questionnaire, analyzed by descriptive statistics and Chi-squared ( $\left.\chi^{2}\right)$ test was used to identify associated independent variables. Z-scores for nutritional statuses were generated using WHO Anthro software. The result revealed that the prevalence of wasting, stunting, underweight and overweight were $2.01 \%, 35.17 \%, 5.27 \%$ and $23.36 \%$ respectively. Immunization status $\left(X^{2}=0.004, p=0.05\right)$ and fathers' educational status $\left(X^{2}=0.018\right.$, $p=0.05$ ) were found statistically significant associated with underweight and stunting respectively. Wasting, stunting and underweight are public health nutritional deficits of children under the age of five in Yirgalem town, Ethiopia. Dimension and degree of already identified associated variables better be addressed using sound study protocol with strong epidemiological and statistical considerations to address limitations of this study before forecast of interventions to reduce under-nutrition in the study area.
\end{abstract}

Keywords: Stunting, under-five children, underweight, wasting

\section{Introduction}

Nutrition is the body's process of taking in and digesting food; using it for growth, reproduction, immunity, breathing, work and health; and storing nutrients and energy in appropriate parts of the body [1]. Nutritional status of children is an indicator of the level of development and future potential of the community. It is the result of complex interactions between food consumption and the overall status of health. Numerous socioeconomic and cultural factors influence patterns of feeding and nutritional status of children. The first five years of children with due emphasis from conception to second birth date are important for optimal growth, health, and development. Unfortunately, this period is often marked by micronutrient deficiencies that interfere with optimal growth [2].

Malnutrition generally refers to both under nutrition and over nutrition. Many factors can cause malnutrition, most of which relate to poor diet or severe and repeated infections, particularly in underprivileged populations. Inadequate diet and disease, in turn, are closely linked to the general standard of living, the environmental conditions, and whether a population is able to meet its basic needs such as food, housing and health care. Malnutrition is thus a health outcome as well as a risk factor for disease and exacerbated malnutrition and it can increase the risk of morbidity and mortality. Although it is rarely the direct cause of death (except in extreme situations, such as famine), child malnutrition was associated with $54 \%$ of child deaths (10.8 million children) in developing countries [3].

According to WHO (2011), under nutrition among children remains common in many parts of the world. About 178 million children under five years worldwide were too short for their age group; while 115 million were underweight. The same report showed that stunting rate among children was higher in Africa and Asia than elsewhere [4]. In Ethiopia, malnutrition is one of the major public health problems and common in children under five years old $[5,6]$.

Malnutrition is one of the leading causes of morbidity and mortality among under five children in developing countries. Ethiopia being among developing countries, malnutrition is an important public health problem. Because this age (under five) is the time were children attain both physical and mental growth rapidly, so this study identified the prevalence and associated factors of nutritional status among under five children.

\section{Objective}

To assess the prevalence of nutritional status and factors associated with nutritional status of under-five children in Yirgalem town, Southern Ethiopia in 2015. 


\subsection{Study design}

\section{Methodology}

A community based cross sectional study was employed on a total of 398 under-five child and mother/caregiver pairs selected using simple random sampling technique. The study was conducted in Yirgalem town, in Sidama Zone, southern part of Ethiopia from March to April 2015. Semi-structured questionnaire was used to collect the data. Weight, height and MUAC of each child were taken by the investigators. Weight for height Z-score (WHZ), height for age Z-score (HAZ) and weight for age Z-score (WAZ) were generated using WHO anthro. Data was enter in to SPSS version 20 for windows, cleaned and checked for completeness and then, after generating descriptive statistics chi-square $\left(\mathrm{X}^{2}\right)$ is used to identify associated independent variables. Letter of permission was obtained from Hawassa University College of Medicine and Health Sciences and submitted to local administrative department before joining the community for data collection. The purpose and importance of the study were explained to each participant and oral consent was secured from each participant (mother/caregiver). Confidentiality was maintained at all levels of the study. Participant involvement in the study was solely voluntary. Those who were unwilling and need to break their participation in between were informed of the freedom with no negative impact for doing so.

\section{Result}

4.1 Socio demographic and housing characteristics

Table 1: Frequency and percentage distribution of studied children

\begin{tabular}{lccc}
\hline \hline Age(months ) * & Male (\%) & Female (\%) & Total (\%) \\
\hline $\mathbf{0 - 5}$ & $14(3.51)$ & $14(3.51)$ & $28(7.03)$ \\
$\mathbf{6 - 1 1}$ & $23(5.77)$ & $24(6.03)$ & $47(11.8)$ \\
$\mathbf{1 2 - 2 3}$ & $29(7.28)$ & $22(5.52)$ & $51(12.81)$ \\
$\mathbf{2 4 - 3 5}$ & $34(8.54)$ & $36(9.04)$ & $70(17.58)$ \\
$\mathbf{3 6 - 4 7}$ & $41(10.3)$ & $70(17.58)$ & $111(27.88)$ \\
$\mathbf{4 8 - 5 9}$ & $47(11.8)$ & $44(11.05)$ & $91(22.86)$ \\
Total & $188(47.23)$ & $210(52.76)$ & $398(100 \%)$ \\
\hline \hline
\end{tabular}

*The median age calculated for both sex is 29.6 .

Table 1 shows that all 398 study subjects were included in the study, out of which $188(47.23 \%)$ were males and $210(52.76 \%)$ were females. The mean age for the study subject was 29.66 months for both sexes.

Table 2: Frequency and percentage distribution of Socio-demographic and housing characteristics of the parents

\begin{tabular}{|c|c|c|}
\hline Variables & Frequency $(n=398)$ & Percentage $(\%)$ \\
\hline \multicolumn{3}{|c|}{ Study subject/mother } \\
\hline One child & 298 & 74.8 \\
\hline Two children & 72 & 18 \\
\hline Three children & 22 & 5.52 \\
\hline Above three & 6 & 1.5 \\
\hline \multicolumn{3}{|l|}{ Educational level } \\
\hline \multicolumn{3}{|l|}{ Mother } \\
\hline Illiterate & 20 & 5 \\
\hline Formal education & 378 & 95 \\
\hline \multicolumn{3}{|l|}{ Father } \\
\hline Illiterate & 3 & 0.8 \\
\hline Formal education & 395 & 99.24 \\
\hline \multicolumn{3}{|c|}{ Occupation of the father } \\
\hline Farmer & 12 & 3 \\
\hline Daily labourer & 90 & 22.6 \\
\hline Civil servant & 195 & 49 \\
\hline Merchant & 92 & 23.1 \\
\hline Others & 09 & 2.3 \\
\hline \multicolumn{3}{|l|}{ Ethnic group } \\
\hline Sidama & 202 & 50.75 \\
\hline Gurage & 66 & 16.6 \\
\hline Amhara & 52 & 13.1 \\
\hline Oromo & 53 & 13.3 \\
\hline Others & 25 & 6.28 \\
\hline \multicolumn{3}{|l|}{ Marital status } \\
\hline Married & 355 & 89.2 \\
\hline Widow & 4 & 1 \\
\hline Divorced & 15 & 3.76 \\
\hline
\end{tabular}


Factors Associated With Nutritional Status of Under-Five Children in Yirgalem Town, Southern ..

\begin{tabular}{|c|c|c|}
\hline Single & 24 & 6 \\
\hline \multicolumn{3}{|l|}{ Religion } \\
\hline Protestant & 172 & 43.2 \\
\hline orthodox & 169 & 42.5 \\
\hline Muslim & 52 & 13.1 \\
\hline Others & 5 & 1.25 \\
\hline \multicolumn{3}{|l|}{ Housing condition } \\
\hline Corrugated & 380 & 95.44 \\
\hline Thatched & 18 & 4.52 \\
\hline \multicolumn{3}{|l|}{ Room } \\
\hline One & 129 & 32.4 \\
\hline Two & 215 & 54 \\
\hline Two or more & 54 & 13.3 \\
\hline \multicolumn{3}{|l|}{ Kitchen } \\
\hline Separate & 369 & 92.7 \\
\hline In living room & 29 & 7.28 \\
\hline \multicolumn{3}{|l|}{ Water source } \\
\hline Protected well & 109 & 27.38 \\
\hline Un protected well & 14 & 3.5 \\
\hline Spring & 85 & 21.35 \\
\hline Pipe & 190 & 47.73 \\
\hline \multicolumn{3}{|l|}{ Latrine } \\
\hline Yes & 398 & 100 \\
\hline No & 0 & 0 \\
\hline
\end{tabular}

Table 2 depicts that a total of 398 mothers responded to the questionnaire, out of this $298(74.87 \%)$ had single child, 72 (18\%) had two children and 22(5.5\%) had three children respectively. Majority $355(89.2 \%)$ of children were born to married couples.

Half, $202(50.8 \%)$ of the respondents belong to Sidama ethnic group, in which, protestant were $172(43.2 \%)$ and orthodox $169(42.5 \%)$. Most of the parents were literate $378(95 \%)$ of the mothers and 299 $(99.2 \%)$ of fathers. The majority of the houses were with corrugated roof 380(95.5\%). Households with only one room constitute $129(32.4 \%)$.

\subsection{Prevalence of Nutritional status of under five children}

The below Fig. 1 pie chart depicts that prevalence of nutritional status among under five children, 21(5.27\%) were underweight (low weight for age), 140(35.17\%) were stunted (low height for age), $8(2.01 \%)$ were wasted (low weight for height) and 93 (23.36\%) were overweight, whereas, 136 (34.17\%) were well nourished.

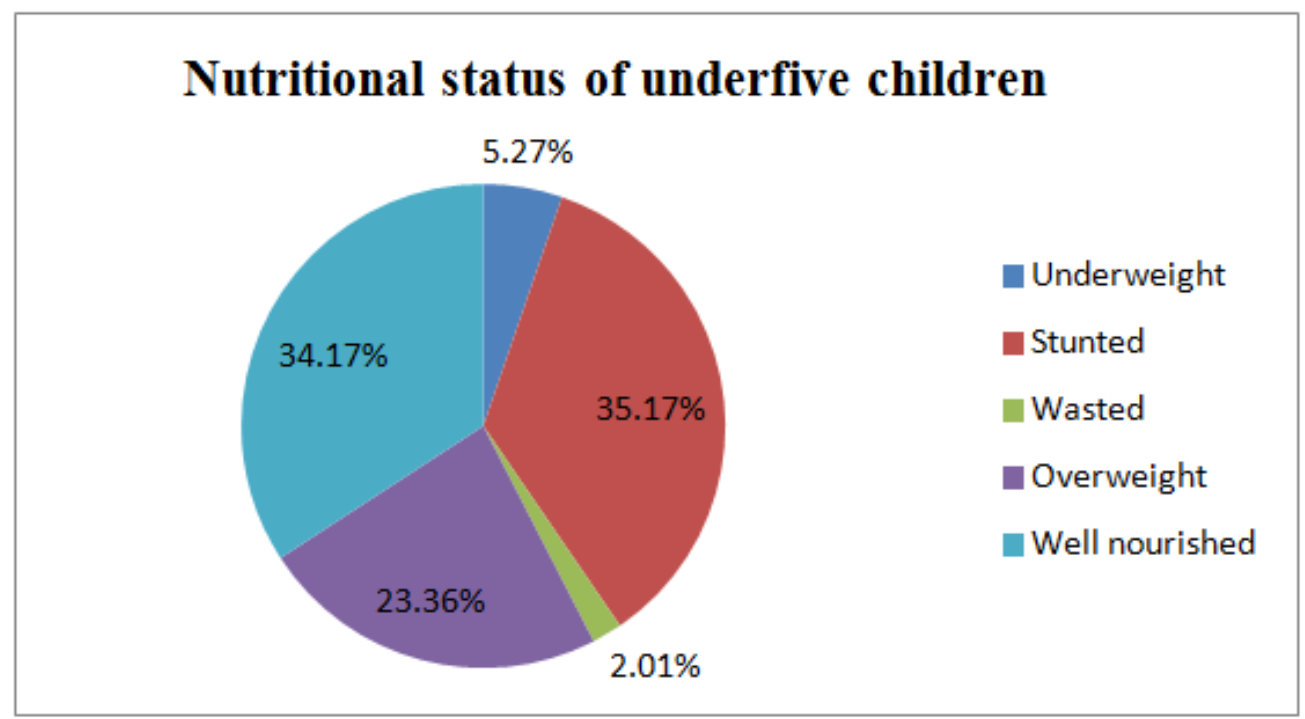

Fig 1: Prevalence of under five children nutritional status

\subsection{Nutritional status of the studied children as measured by WHZ in relation to WHO standard}

Fig. 2 illustrates that the nutritional status as measured by weight for height (WHZ) of the studied children in relation to the WHO standard. The figure shows shift to the right of the WHO curve which means the children are over nourished (overweight) in relation to the curve. 


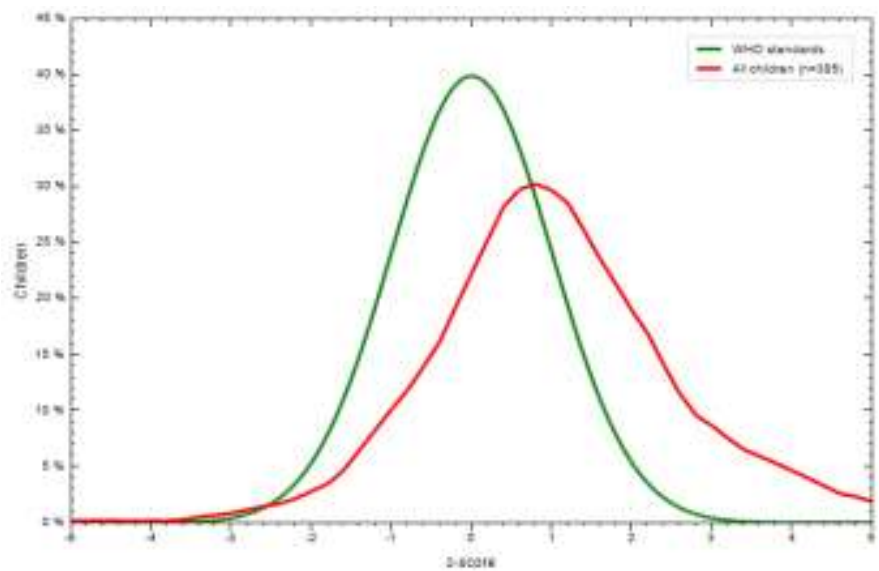

Fig 2: Nutritional status of the studied children as measured by WHZ in relation to WHO standard

\subsection{Nutritional status of the studied children as measured by $\mathrm{HAZ}$ in relation to WHO standard}

Figure 3 depicts nutritional status of the studied children as measured by Height for age (HAZ). The shift of the graph in the figure shows shift to the left, the children are undernourished (stunted) in relation to the WHO curve.

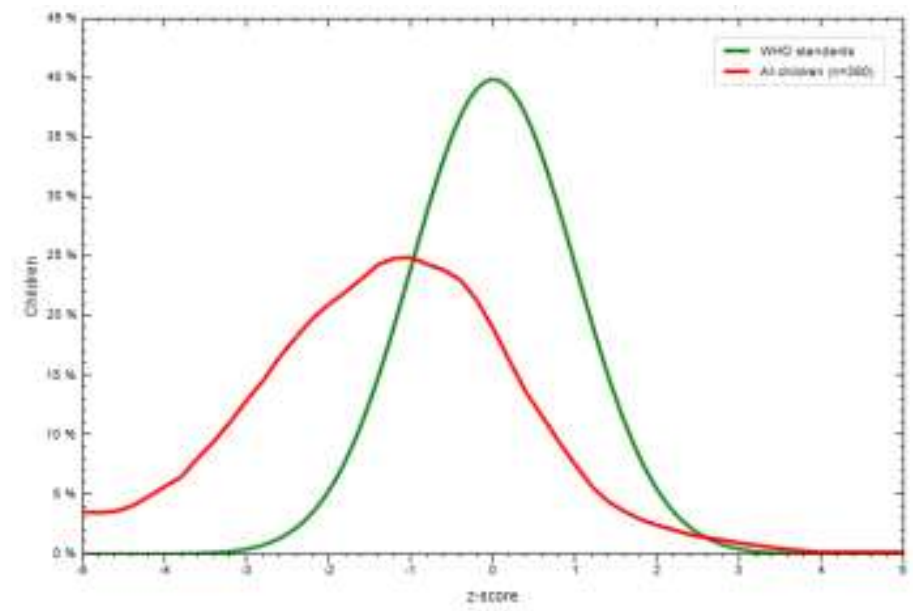

Fig 3: Nutritional status of the studied children as measured by HAZ in relation to WHO standard

4.5 Nutritional status of the studied children as measured by WAZ in relation to WHO standard

Fig 4 depicts that the nutritional status of the children as measured by weight for age (WAZ). It can be seen from the figure that the children are almost normal (well nourished) in relation to the curve provided by WHO.

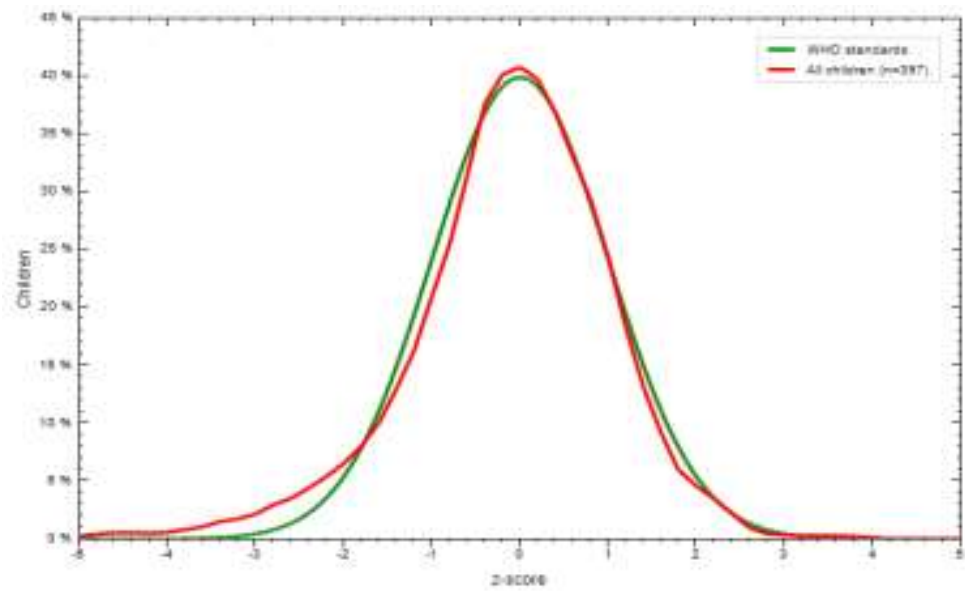

Fig 4: Nutritional status of the studied children as measured by WAZ in relation to WHO standard 
Factors Associated With Nutritional Status of Under-Five Children in Yirgalem Town, Southern ..

4.6 Nutritional status as measured by MUAC

Among 370 children eligible for MUAC, 31 (7.8\%) were found to be malnutrition as measured by MUAC.

\subsection{Factors associated with nutritional status of under five children}

Table 3: Factors associated with nutritional status as measured by Height for Age $(n=398)$ among under five children

\begin{tabular}{|c|c|c|c|c|}
\hline \multirow[t]{2}{*}{ Variables } & \multicolumn{2}{|c|}{ HAZ } & \multirow[t]{2}{*}{ Chi-square } & \multirow[t]{2}{*}{ P value } \\
\hline & Well nourished & Malnourished & & \\
\hline \multicolumn{3}{|l|}{ Age in month } & \multirow{3}{*}{3.303} & \multirow{3}{*}{0.069} \\
\hline$<29$ month & $110(27.63 \%)$ & $73(18.34 \%)$ & & \\
\hline$\geq 29$ month & $148(37.18 \%)$ & $67(16.84 \%)$ & & \\
\hline \multicolumn{3}{|l|}{ Sex of under five } & \multirow{3}{*}{2.738} & \multirow{3}{*}{0.098} \\
\hline Female & $144(36.18 \%)$ & $66(16.58 \%)$ & & \\
\hline Male & $114(28.64 \%)$ & $74(18.59 \%)$ & & \\
\hline \multicolumn{3}{|l|}{ Marital status } & \multirow{5}{*}{4.478} & \multirow{5}{*}{0.214} \\
\hline Married & $234(58.79 \%)$ & $121(30.4 \%)$ & & \\
\hline Single & $15(3.76 \%)$ & $9(2.26 \%)$ & & \\
\hline Divorced & $6(1.5 \%)$ & $9(2.26 \%)$ & & \\
\hline widowed & $3(0.75 \%)$ & $1(0.25 \%)$ & & \\
\hline \multicolumn{3}{|l|}{ Age at first marriage } & \multirow{3}{*}{0.771} & \multirow{3}{*}{0.380} \\
\hline$\leq 18$ years & $108(27.13 \%)$ & $65(16.33 \%)$ & & \\
\hline$\geq 19$ years & $150(37.86 \%)$ & $75(18.84 \%)$ & & \\
\hline \multicolumn{3}{|l|}{ Father's occupation } & \multirow{3}{*}{0.52} & \multirow{3}{*}{0.820} \\
\hline Employed & $255(64.07 \%)$ & $138(34.67 \%)$ & & \\
\hline Unemployed & $3(0.75 \%)$ & $2(0.5 \%)$ & & \\
\hline \multicolumn{3}{|l|}{ Mother's occupation } & \multirow{3}{*}{0.27} & \multirow{3}{*}{0.870} \\
\hline Employed & $136(34.17 \%)$ & $75(18.84 \%)$ & & \\
\hline Un employed & $122(30.65 \%)$ & $65(16.33 \%)$ & & \\
\hline \multicolumn{3}{|l|}{ Ethnicity } & & \\
\hline Sidama & $133(33.41 \%)$ & $69(17.33 \%)$ & & \\
\hline Gurage & $45(11.3 \%)$ & $21(5.27 \%)$ & 6.279 & 0.616 \\
\hline Oromo & $29(7.28 \%)$ & $24(6.03 \%)$ & & \\
\hline Amhara & $32(8.04 \%)$ & $20(5 \%)$ & & \\
\hline Father's education & & & & \\
\hline Illiterate & $3(0.75 \%)$ & 0 & 5.571 & 0.018* \\
\hline Formal education & $258(64.82 \%)$ & $137(34.42 \%)$ & & \\
\hline Mother's education & & & & \\
\hline Illiterate & $14(3.51 \%)$ & $6(1.5 \%)$ & 0.247 & 0.619 \\
\hline Formal education & $244(61.3 \%)$ & $134(33.66 \%)$ & & \\
\hline Income in month & & & & \\
\hline$<1000$ birr & $135(33.9 \%)$ & $66(16.58 \%)$ & 0.975 & 0.323 \\
\hline$\geq 1001$ birr & $123(30.9 \%)$ & $74(18.59 \%)$ & & \\
\hline Immunization statu & & & & \\
\hline Immunized & $227(57.03 \%)$ & $120(30.15 \%)$ & 0.419 & 0.518 \\
\hline Partially immunized & $31(7.78 \%)$ & $20(5 \%)$ & & \\
\hline Religion & & & & \\
\hline Orthodox & $113(28.39 \%)$ & $56(14.07 \%)$ & & \\
\hline Protestant & $106(26.63 \%)$ & $66(16.58 \%)$ & 3.799 & 0.434 \\
\hline Muslim & $34(8.54 \%)$ & $18(4.5 \%)$ & & \\
\hline Supplementary star & & & & \\
\hline$<6$ month & $53(13.31 \%)$ & $36(9.04 \%)$ & & \\
\hline $7-9$ month & $163(40.95 \%)$ & $93(40.95 \%)$ & 3.364 & 0.186 \\
\hline$\geq 10$ month & $17(4.27 \%)$ & $4(1 \%)$ & & \\
\hline
\end{tabular}

* $\mathrm{P}$ value, value for which $<0.05$ is significantly associated

Table 3 reveals that father's education was significantly associated with height for age (stunting) of under five children

Table 4: Factors associated with nutritional status as measured by Weight for Age ( $\mathrm{n}=398)$ among under five children

\begin{tabular}{|l|l|l|l|l|}
\hline \multirow{2}{*}{ Variables } & \multicolumn{2}{|c|}{ WAZ } & \multirow{2}{*}{ Chi-square } & \multirow{2}{*}{ P value } \\
\cline { 2 - 3 } & Well nourished & Malnourished & \multirow{2}{*}{5.781} & \multirow{2}{*}{0.16} \\
\hline Age in month & & & \\
\hline$<29$ month & $168(42.2 \%)$ & $15(3.76 \%)$ & & \multirow{2}{*}{0.167} \\
\hline$\geq 29$ month & $209(52.5 \%)$ & $6(1.5 \%)$ & \multirow{2}{*}{0.14} \\
\hline Sex of under five & & & & \\
\hline Female & $202(50.75 \%)$ & $8(2 \%)$ & $13(3.26 \%)$ & \\
\hline Male & $175(43.96 \%)$ & &
\end{tabular}


Factors Associated With Nutritional Status of Under-Five Children in Yirgalem Town, Southern ..

\begin{tabular}{|c|c|c|c|c|}
\hline Marital status & & & \multirow{5}{*}{1.208} & \multirow{5}{*}{0.751} \\
\hline Married & $335(84.14 \%)$ & $20(5 \%)$ & & \\
\hline Single & $23(5.77 \%)$ & $1(0.25 \%)$ & & \\
\hline Divorced & $15(3.76 \%)$ & 0 & & \\
\hline widowed & $4(1 \%)$ & 0 & & \\
\hline \multicolumn{3}{|l|}{ Age at first marriage } & \multirow{3}{*}{0.003} & \multirow{3}{*}{0.954} \\
\hline$\leq 18$ years & $164(41.2 \%)$ & $9(2.26 \%)$ & & \\
\hline$\geq 19$ years & $213(53.5 \%)$ & $12(3 \%)$ & & \\
\hline \multicolumn{3}{|l|}{ Father's occupation } & \multirow{3}{*}{0.282} & \multirow{3}{*}{0.595} \\
\hline Employed & $372(93.46 \%)$ & $21(5.27)$ & & \\
\hline Unemployed & $5(1.25 \%)$ & 0 & & \\
\hline \multicolumn{3}{|l|}{ Mother's occupation } & \multirow{3}{*}{0.259} & \multirow{3}{*}{0.611} \\
\hline Employed & $201(50 \%)$ & $10(2.51 \%)$ & & \\
\hline Unemployed & $176(44.22 \%)$ & $11(2.76 \%)$ & & \\
\hline \multicolumn{3}{|l|}{ Ethnicity } & \multirow{5}{*}{3.631} & \multirow{5}{*}{0.889} \\
\hline Sidama & $188(47.23 \%)$ & $14(3.5 \%)$ & & \\
\hline Gurage & $64(16.08 \%)$ & $2(0.5 \%)$ & & \\
\hline Oromo & $52(13.06)$ & $1(0.25 \%)$ & & \\
\hline Amhara & $49(12.3 \%)$ & $3(0.75 \%)$ & & \\
\hline \multicolumn{3}{|l|}{ Father's education } & \multirow{3}{*}{4.761} & \multirow{3}{*}{0.29} \\
\hline Illiterate & $2(0.5 \%)$ & $1(0.25 \%)$ & & \\
\hline Formal education & $375(94.22 \%)$ & $20(5.02 \%)$ & & \\
\hline \multicolumn{3}{|l|}{ Mother's education } & \multirow{3}{*}{0.003} & \multirow{3}{*}{0.955} \\
\hline Illiterate & $19(4.77 \%)$ & $1(0.25 \%)$ & & \\
\hline Formal education & $358(89.9 \%)$ & $20(5.02 \%)$ & & \\
\hline \multicolumn{3}{|l|}{ Income in month } & \multirow{3}{*}{0.74} & \multirow{3}{*}{0.786} \\
\hline$<1000$ birr & $191(47.98 \%)$ & $10(2.51 \%)$ & & \\
\hline$\geq 1001$ birr & $186(46.7 \%)$ & $11(2.76 \%)$ & & \\
\hline \multicolumn{3}{|l|}{ Immunization status } & \multirow{3}{*}{8.355} & \multirow{3}{*}{$0.004 *$} \\
\hline Immunized & $333(83.66 \%)$ & $14(3.5 \%)$ & & \\
\hline Partially immunized & $44(11 \%)$ & $7(1.75 \%)$ & & \\
\hline \multicolumn{3}{|l|}{ Religion } & & \\
\hline Orthodox & $163(40.95 \%)$ & $6(1.5 \%)$ & 2.306 & 0.680 \\
\hline Protestant & $160(40.2 \%)$ & $12(3 \%)$ & & \\
\hline Muslim & $49(12.3 \%)$ & $3(0.75 \%)$ & & \\
\hline Supplementary star & & & & \\
\hline$<6$ month & $82(20.6 \%)$ & $7(1.75 \%)$ & & \\
\hline $7-9$ month & $247(62.06 \%)$ & $9(2.261 \%)$ & 2.822 & 0.244 \\
\hline$\geq 10$ month & $20(5.02 \%)$ & $1(0.25 \%)$ & & \\
\hline
\end{tabular}

$* \mathrm{P}$ value, value for which $<0.05$ is significantly associated

Table 4 illustrates that immunization status was significantly associated with weight for age (underweight) of under five children.

\section{Discussion}

The present study was conducted to assess factors associated with nutritional status of under-five children in Yirgalem town, southern Ethiopia. Community based cross-sectional study revealed that the overall prevalence rate of malnutrition in the study population was high. Some of the study subjects were affected by more than one type of malnutrition. The prevalence of underweight was low when compared to the report of nationwide survey conducted which showed $25 \%$ and $26.3 \%$ of the national and regional report of underweight children in the similar age group .On the other hand the prevalence of wasting was very high $37.28 \%$ when compared to both the national and the regional figure $11 \%$ and $10 \%$ respectively [7].

The result of the study was comparable to Somalian study which showed $34.4 \%$ of the children were stunted and $42.3 \%$ were wasted even though the rate of underweight $47.7 \%$ was higher than our findings [8]. This may be due to different socio-economic and cultural factors between the two communities. The study result was different to the finding of 22 developing countries that were done in 1985, which showed prevalence rate of $39 \%$ below reference median weight-for-age which is much higher than our finding 5.3\% [9].

The descriptive statistics result showed malnutrition increased with age in both sexes up to the age of three and then relatively decreases as age increases. This is in agreement with the report from India which showed the nature of malnutrition to be strongly dependent on age [10]. The result of study showed a significant association between father's education and immunization status of the children and prevalence of malnutrition. The social variables studied, immunization and father's educational level were the two factors that showed the strongest association with the nutritional status [11]. The study did not show significant association between malnutrition and type of housing (type of roof and number of rooms). 


\section{Conclusion}

The findings of the present study indicated that the magnitude of malnutrition in the study population was high. The prevalence of wasting, stunting and underweight $(<-2 \mathrm{SD})$ by WHO standards was $37.8 \%$, $35.142 \%$ and $5.3 \%$ respectively. Factors significantly influencing nutritional status in the study population found to be father's educational status and immunization status of the child. This calls for collaboration of different sectors of society for ensuring educational coverage specially fathers of children and ensuring adequate provision of immunization based on the expanded program on immunization.

\section{References}

[1] Wikibooks, Human Physiology/The gastrointestinal system, https://en.wikibooks.org/wiki/Human_Physiology/The_gastrointestinal _system

[2] Ergin F, Okyay P, Atasoylu G, Beser E. Nutritional status and risk factors of chronic malnutrition in children under five years of age in Aydin, a western city of Turkey. The Turkish Journal of Pediatrics 2007; 49(3):283-289

[3] Blössner, Monika, de Onis, Mercedes. Malnutrition: quantifying the health impact at national and local levels. Geneva, World Health Organization, 2005. WHO Environmental Burden of Disease Series, No. 12.

[4] World Health Organization (WHO). 2011. World Health Statistics. World Health Organization, Geneva, Switzeraland

[5] Hailemariam A and Kloos H. Population. In: Kloos H; Zein Az. eda. The Ecology of Health and Disease in Ethiopia. Westview press 1993: 43-66.

[6] Bekele A, Wolde-Gebriel Z, and Kloos H. Food, Diet, and Nutrition. The Ecology of Health and Disease in Ethiopia. Westview press 1993: 85-102.

[7] Central Statistical Agency [Ethiopia]. 2014. Ethiopia Mini Demographic and Health Survey 2014. Addis Ababa, Ethiopia.

[8] Solomon Demissie, Amare Worku, Magnitude and factors associated with malnutrition in children 6-59 months of age in pastoral community of Dollo Ado district, Somali region, Ethiopia.2013

[9] Haaga et al. An estimate of the prevalence of child malnutrition in developing countries. World Health Statistics quarterly; 35: $1985,332-347$.

[10] Steinhoff M C, Hilder A S, Strilatha V L, and Mukarji D. Prevalence of malnutrition in Indian pre-school age children: a survey of wasting and stunting in rural Tamil Nadu. Bulletin of WHO; 64(3), 1986: 457-463.

[11] Cesar G V, Patrick J V, Betty R K W., Jose C M. Risk factors for malnutrition in Brazilian children: the role of social and environmental variable. Bulletin of WHO; 64(2), 1986: 299-309. 